\title{
The Effect of High-Intensity Interval Training and Continuous Training on the Desnutrin Gene Expression in the Subcutaneous Adipose Tissue and the Quadriceps Femoris Muscle Tissue of Obese Male Rats
}

\author{
${ }^{1}$ Saeed Rahmaty ${ }^{*},{ }^{1}$ Abbas Ali Gaeini, ${ }^{2}$ Mojtaba Dolatshahi, ${ }^{1}$ Siroos Choobineh \\ ${ }^{1}$ Department of Exercise Physiology, Faculty of Sport Sciences, University of Tehran, Tehran, Iran. ${ }^{2}$ Department of \\ Medical Physiology, Faculty of Medical Sciences, Dezful University of Medical Sciences, Dezful, Iran.
}

\begin{abstract}
Background. Desnutrin is an enzyme that catalyzes the first step of cytoplasmic triacylglycerol lipolysis from white adipose tissue and several other tissues, which are disrupted by the obesity and metabolic syndrome. Objectives. The aim of this study was to compare the effect of high-intensity interval training and continuous training on the desnutrin gene expression in the subcutaneous adipose tissue and the quadriceps muscle tissue of obese male rats. Methods. For this purpose, after 12 weeks on a high-fat diet, 30 Wistar rats were divided into two groups: continuous training $(\mathrm{n}=10)$ and high-intensity interval training $(\mathrm{n}=10)$. Continuous $(80 \% \mathrm{VO} 2 \mathrm{max})$ and high-intensity interval exercise training (100\%VO2max) sessions were conducted according to the principle of overload for six weeks and six sessions per week. Forty-eight hours after the last training session, the abdominal subcutaneous adipose tissue and quadriceps muscle tissue were extracted, and the expression level was assessed using the RT-PCR method. Results. The study showed that the difference between high-intensity interval and continuous training on the desnutrin gene expression subcutaneous adipose tissue was significant $(\mathrm{p}=0.004)$, but there were no significant differences $(\mathrm{p}=0.415)$ between them in the quadriceps femoris muscle tissue. Conclusion. According to the findings of the present study, in the adipose tissue, continuous training has a greater effect on the desnutrin gene expression than high-intensity interval training. In the muscle tissue, however, there is no difference between these two training exercises.
\end{abstract}

KEY WORDS: Desnutrin, Continuous Training, High-Intensity Interval Training, Lipolysis, Obesity.

\section{INTRODUCTION}

Obesity is associated with serious illnesses such as noninsulin-dependent diabetes, increased blood lipids, high blood pressure, cancer, and cardiovascular diseases, and is a major health problem. This is why, clinical attention has been drawn to it today (1). Fourteen years ago (2004), a new lipolytic enzyme called desnutrin/ATGL was discovered in mice. Further studies showed that the process of conversion of triacylglycerol lipolysis to diacylglycerol and fatty acid begins with desnutrin/ATGL, not HSL(2). The molecular weight of desnutrin is $53.6 \mathrm{KD}$, which consists of 486 amino acids (3).However, desnutrin has 19 more amino acids in humans(3). Other names of this protein includeIPLA2 and adipose triglyceride lipase (ATGL), which, in

*. Corresponding Author:

Saeed Rahmaty

E-mail: s_rahmaty4290@yahoo.com 
humans, is termed as ATGL (3). Desnutrin regulates adipose tissue lipolysis in response to nutritional conditions (low energy under a fasting condition) (3). Its major expression region is the cytoplasm of the white adipose and the brown adipose tissue $(2,4)$. However, it is also expressed in other tissues of the body, including the liver and the skeletal muscle tissue $(2,4)$. Studies show that there is an inverse relationship between the levels of the desnutrin gene expression, obesity, and diabetes. A low level of this enzyme is associated with an increase in body fat and following the increase of TG stores increases the insulin resistance (5). Desnutrin plays a role in the first step of lipolysis within the conversion of triglyceride to diglyceride $(2,4)$. Furthermore, in in vitro studies, it has been shown that the desnutrin affinity to triglyceride is 10 times higher than its affinity to diglyceride; therefore, desnutrin is considered to be the restriction enzyme of the triglyceride hydrolysis level in the adipose and the muscle tissue(4).

Studies show that the high desnutrin enzyme expression is associated with the level of brown adipose. Hence, the increase of its expression leads to an increase in the expression of UCP1 and FA oxidation. As a result, desnutrinis effective in the maintenance of the brown adipose phenotype (6). For example, Ahmadian et al. (2011) showed that the ablation of the desnutrin enzyme in micecauses the conversion of brown adipose tissue to white adipose tissue, which is followed by impairment in thermogenesis and a severe increase of the genes expression associated with the white adipose tissue phenotype. As a result, it was established that the lipolysis resulting from desnutrin was necessary to maintain the brown adipose tissue phenotype (6). Moreover, there is a direct and positive relationship between desnutrin and fat oxidation markers (CPT1, PGC1- $\alpha, \mathrm{UCP} 1$, and cytochrome oxidase c) in the skeletal muscle, suggesting that the increase in intramuscular desnutrin/ATGL can lead to greater oxidation of fatty acids $(7,8)$. A high-fat diet and resulting obesity causes impairment in lipolysis markers (ATGL, HSL, and CGI-58), and leads to insulin resistance and other obesity-related health problems $(5,6,9)$. So, the present study focuses on obesity.

Various studies have been performed on the effect of exercise on fat loss. Moreover, high- intensity interval training (HIIT) is a form of training that includes repetitive extreme exercises and active or inactive breaks; today, it is considered an effective fat-loss method (10). Studies show that HIIT can produce comparable effects to continuous traditional training, but with shorter time requirements, in the muscle oxidative capacity, the ability to access substrate, and the fat loss of the entire body $(10,11)$. For example, Zhang et al. (2017) compared the effects of 12 weeks and the three sessions of HIIT training per week and the prolonged continuous exercise training on fat loss in obese young women. The amount of fat loss was same in both methodswith the difference that the time spent on HIIT was much shorter (11). HIIT, therefore, is a more effective and economical exercise protocol for reducing body fat in comparison to prolonged continuous exercise training (11).

So far, the effect of the HIIT training on desnutrin/ATGL has been rarely studied. However, the effect of endurance training exercises with or without a high-fat diet has been studied. For example, Larsen et al. (2015) showed that six weeks and three sessions of high-intensity interval training (HIIT) per week have no effect on the level of ATGL and mitochondrial fat oxidation in muscle tissue and the subcutaneous fatty tissue of inactive overweight human subjects (7).

According to the importance of desnutrin in fat metabolism, research literature shows that there is an inverse relationship between desnutrin, obesity, and diabetes. In addition, many studies on the effect of exercise training on body fat loss studied the impact of aerobic and continuous exercises training on desnutrin/ATGL $(5,12)$; so far, however, less research has been performed on the effect of HIIT exercise training on desnutrin in adipose and muscle tissues, simultaneously. Therefore, the aim of this study was to compare the effect of six weeks of continuous training with high-intensity interval training on the desnutrin gene expression of the subcutaneous adipose tissue and the quadriceps femoris muscle tissue of obese male rats.

\section{MATERIALS AND METHODS}

Animals. The type of research was fundamental and its method was experimental. Thirty adult (10-week-old) male Wistar rats, with an average weight of $220 \pm 5 \mathrm{~g}$, were purchased 
from the Pasteur Institute. After one week of familiarization with environment, the obesity process (which lasted for 12 weeks), and the implementation method (which is described in the following section), the rats were randomly divided into two groups:

1) Group 1: Included10 rats which exercised for six weeks and six sessions of continuous training per week, while consuming the standard diet (continuous training).

2) Group 2: Included10 rats which exercised for six weeks and six sessions of high-intensity interval training per week while consuming the standard diet (interval training).
Training Protocols. Continuous training and the high-intensity interval training group ran for six weeks and six sessions per week on the treadmill. The control group did not have any exercise at all. Exercise training was performed on a 12-lane treadmill. As we had to control the intensity and the duration of the exercise comfortably, the rats were first exposed to the treadmill for a week (10 minutes at speed of $10 \mathrm{~m} /$ minute and five days a week).Continuous training and high-intensity interval training were conducted for six weeks and six sessions per week according to the principle of overload (13) (Table 1).

Table 1. Continuous training and high-intensity interval training protocols.

\begin{tabular}{|c|c|c|c|c|}
\hline \multirow{2}{*}{ Week } & \multirow{2}{*}{ day } & \multirow{2}{*}{$\mathrm{CT}$} & \multicolumn{2}{|c|}{ HIIT } \\
\hline & & & Odd day & Even day \\
\hline \multirow[t]{6}{*}{ Week1 } & 1 & $20 \mathrm{~min}, 27 \mathrm{~m} / \mathrm{min}$ & \multirow{2}{*}{2 intervals, $40 \mathrm{~m} / \mathrm{min}, 3 \mathrm{~min}$} & \multirow{2}{*}{3 intervals, $54 \mathrm{~m} / \mathrm{min}, 30 \mathrm{~s}$} \\
\hline & 2 & $22 \mathrm{~min}, 27 \mathrm{~m} / \mathrm{min}$ & & \\
\hline & 3 & $24 \mathrm{~min}, 27 \mathrm{~m} / \mathrm{min}$ & \multirow[t]{2}{*}{2 intervals $, 40 \mathrm{~m} / \mathrm{min}, 3 \mathrm{~min}$} & \multirow{2}{*}{5 intervals, $54 \mathrm{~m} / \mathrm{min}, 30 \mathrm{~s}$} \\
\hline & 4 & $26 \mathrm{~min}, 27 \mathrm{~m} / \mathrm{min}$ & & \\
\hline & 5 & $28 \mathrm{~min}, 27 \mathrm{~m} / \mathrm{min}$ & \multirow[t]{2}{*}{2 intervals, $40 \mathrm{~m} / \mathrm{min}, 3 \mathrm{~min}$} & \multirow{2}{*}{7 intervals, $54 \mathrm{~m} / \mathrm{min}, 30 \mathrm{~s}$} \\
\hline & 6 & $30 \mathrm{~min}, 27 \mathrm{~m} / \mathrm{min}$ & & \\
\hline \multirow[t]{6}{*}{ Week2 } & 1 & $32 \mathrm{~min}, 27 \mathrm{~m} / \mathrm{min}$ & \multirow[t]{2}{*}{3 intervals, $40 \mathrm{~m} / \mathrm{min}, 3 \mathrm{~min}$} & \multirow{2}{*}{9 intervals, $54 \mathrm{~m} / \mathrm{min}, 30 \mathrm{~s}$} \\
\hline & 2 & $34 \mathrm{~min}, 27 \mathrm{~m} / \mathrm{min}$ & & \\
\hline & 3 & $36 \mathrm{~min}, 27 \mathrm{~m} / \mathrm{min}$ & \multirow[t]{2}{*}{3 intervals $, 40 \mathrm{~m} / \mathrm{min}, 3 \mathrm{~min}$} & \multirow{2}{*}{11 intervals, $, 54 \mathrm{~m} / \mathrm{min}, 30 \mathrm{~s}$} \\
\hline & 4 & $38 \mathrm{~min}, 27 \mathrm{~m} / \mathrm{min}$ & & \\
\hline & 5 & $40 \mathrm{~min}, 27 \mathrm{~m} / \mathrm{min}$ & \multirow[t]{2}{*}{3 intervals, $40 \mathrm{~m} / \mathrm{min}, 3 \mathrm{~min}$} & \multirow{2}{*}{13 intervals, $, 54 \mathrm{~m} / \mathrm{min}, 30 \mathrm{~s}$} \\
\hline & 6 & $42 \mathrm{~min}, 27 \mathrm{~m} / \mathrm{min}$ & & \\
\hline \multirow[t]{6}{*}{ Week3 } & 1 & $44 \mathrm{~min}, 27 \mathrm{~m} / \mathrm{min}$ & \multirow[t]{2}{*}{4 intervals, $40 \mathrm{~m} / \mathrm{min}, 3 \mathrm{~min}$} & \multirow{2}{*}{15 intervals, $, 54 \mathrm{~m} / \mathrm{min}, 30 \mathrm{~s}$} \\
\hline & 2 & $46 \mathrm{~min}, 27 \mathrm{~m} / \mathrm{min}$ & & \\
\hline & 3 & $48 \mathrm{~min}, 27 \mathrm{~m} / \mathrm{min}$ & \multirow[t]{2}{*}{4 intervals $, 40 \mathrm{~m} / \mathrm{min}, 3 \mathrm{~min}$} & \multirow{2}{*}{17 intervals, $, 54 \mathrm{~m} / \mathrm{min}, 30 \mathrm{~s}$} \\
\hline & 4 & $50 \mathrm{~min}, 27 \mathrm{~m} / \mathrm{min}$ & & \\
\hline & 5 & $52 \mathrm{~min}, 27 \mathrm{~m} / \mathrm{min}$ & \multirow[t]{2}{*}{5 intervals, $40 \mathrm{~m} / \mathrm{min}, 3 \mathrm{~min}$} & \multirow[t]{2}{*}{19 intervals, $, 54 \mathrm{~m} / \mathrm{min}, 30 \mathrm{~s}$} \\
\hline & 6 & $54 \mathrm{~min}, 27 \mathrm{~m} / \mathrm{min}$ & & \\
\hline \multirow[t]{4}{*}{ Week4 } & $\begin{array}{l}1 \\
2\end{array}$ & $\begin{array}{l}56 \mathrm{~min}, 27 \mathrm{~m} / \mathrm{min} \\
58 \mathrm{~min}, 27 \mathrm{~m} / \mathrm{min}\end{array}$ & 5 intervals, $40 \mathrm{~m} / \mathrm{min}, 3 \mathrm{~min}$ & 19 intervals, $, 54 \mathrm{~m} / \mathrm{min}, 30 \mathrm{~s}$ \\
\hline & 3 & $60 \mathrm{~min}, 27 \mathrm{~m} / \mathrm{min}$ & \multirow[t]{2}{*}{6 intervals $, 40 \mathrm{~m} / \mathrm{min}, 3 \mathrm{~min}$} & \multirow{2}{*}{20 intervals, $, 54 \mathrm{~m} / \mathrm{min}, 30 \mathrm{~s}$} \\
\hline & 4 & $60 \mathrm{~min}, 27 \mathrm{~m} / \mathrm{min}$ & & \\
\hline & $\begin{array}{l}5 \\
6\end{array}$ & $\begin{array}{l}60 \mathrm{~min}, 27 \mathrm{~m} / \mathrm{min} \\
60 \mathrm{~min}, 27 \mathrm{~m} / \mathrm{min}\end{array}$ & 6 intervals $, 40 \mathrm{~m} / \mathrm{min}, 3 \mathrm{~min}$ & 20 intervals, $, 54 \mathrm{~m} / \mathrm{min}, 30 \mathrm{~s}$ \\
\hline Week5- & $1-$ & $60 \mathrm{~min}, 27 \mathrm{~m} / \mathrm{min}$, to & 6 intervals, $40 \mathrm{~m} / \mathrm{min}, 3 \mathrm{~min}$ & \\
\hline 6 & 12 & end of $6^{\text {th }}$ week & , to end of $6^{\text {th }}$ week & $\begin{array}{l}20 \mathrm{~min},, 54 \mathrm{~m} / \mathrm{min}, 30 \mathrm{~s} \text {, to } \\
\text { end of } 6^{\text {th }} \text { week }\end{array}$ \\
\hline
\end{tabular}

Overload was applied to continuous training (CT) by increasing the time duration and by adding intervals to high-intensity interval training (HIIT).At the beginning and the end of the continuous training program as well as the high- intensity interval training, warm-up and cool-down activities were conducted for 60 seconds at a speed of $16 \mathrm{~m} /$ minute. This intensity is $68 \% \mathrm{VO} 2 \mathrm{max}$ (13). Moreover, the intensities of the continuous and the high-intensity interval program were 
respectively $\quad 80 \% \quad \mathrm{VO} 2 \mathrm{maxand} \quad 95-100 \%$ VO2max.In the HIIT group, there were 60 seconds of active rest between the intervals, with a speed of $16 \mathrm{~m} /$ minute. The rats were monitored throughout the training sessions and were encouraged to continue running by using a weak electrical shock (intensity of $0.5 \mathrm{~mA}$ ) that did not create much stress in them and was placed at the back of the treadmill; the rats were also manipulated using a sponge. Each animal was assigned an exclusive lane; therefore, all its training program activities were conducted on a specific lane. This minimized the factors that could confuse the rat. Control group rats did not have any daily activities.

The rats were kept in the animal lab of Dezful Jundishapur University of Medical Sciences under controlled light conditions (12 hours of light starting from 6 A Mand 12 hours of darkness starting from $6 \mathrm{PM})$, temperature $\left(22 \pm 3^{\circ} \mathrm{C}\right)$, and humidity (about 45\%). Owing to the lack of prepared high-fat food for rats in Iran, high-fat food were made in the form of pellets, using the analysis of standard food by considering the instructions of high-fat diet articles and under the guidance of poultry experts. High-fat diet consisted of $69 \%$ energy from fat, $21 \%$ energy from protein, and 20\% energy from carbohydrates (14). In addition to food, a rat needed $10-12 \mathrm{ml}$ of water per100 $\mathrm{g}$ of its own body weight daily. For this purpose, the water in the $500 \mathrm{ml}$ bottle was changed every day. For twelve weeks, the rats consumed a diet with high-fat and energy known as a high-energy diet (HE).This diet (HE) contained 5.2 kilocalories per gram of the rat's body weight. Moreover, the rats in the training group and the control group consumed rat standard diet (chow) for 6 weeks of the training protocol. The rats were kept in separate in Plexiglas cages with the dimensions $25 \times 27 \times 43 \mathrm{~cm}$, with a wire door through which the rats were free to access the water and the food that they were provided. The weighing of rats was performed on a weekly basis throughout the research period, including the obesity and the protocol training process.
Throughout the research, the rats were also displaced and manipulated by a person. All the keeping and killing procedures of rats were conducted according to the Animal Ethics Committee terms of Dezful University of Medical Sciences (IR.DUMS.REC.1396.21).

Tissue Extraction. In order to avoid misinterpretation of the data due to the remaining effects of the last exercise training session, the rats were executed after 48 hours of the last training session by cutting off their heads while being kept under deep anesthesia (ketamine, 60-80 mg per kg of body weight; and xylazine, $8 \mathrm{mg}$ per $\mathrm{kg}$ of body weight).In this study, a biopsy of the subcutaneous adipose tissue and the quadriceps femoris muscle was conducted. The target tissues were extracted from each rat in less than five minutes and washed well using normal saline solution to remove extra blood; the tissues were weighed using a $0.0001 \mathrm{~g}$ digital scale. Then, the tissues were immediately frozen at $-80{ }^{\circ} \mathrm{C}$ for further measurements using frozen liquid nitrogen.

RNA Extraction and Real Time-PCR. RNA extraction was conducted using a trizol solution and a tissue homogenizer device. For the quantitative measurement of extracted RNA, a Nano Drop device with a wavelength range of 260-280 nm was used. The average ratio of OD in the wavelength of $260-280 \mathrm{~nm}$ was 1.90 , which indicated the proper quality and purity of the extracted RNA. To make cDNA, the TaKaRa Kit instructions were followed. The samples were then loaded into the thermal cycler for one hour at $37^{\circ} \mathrm{C}$ and five minutes at $85^{\circ} \mathrm{C}$. For quantitative RT-PCR, the samples were first incubated for 10 minutes at $95^{\circ} \mathrm{C}$.Then, the following three steps were repeated 40 times: 30 seconds of $95^{\circ} \mathrm{C}$ for denaturation, 30 seconds of $58^{\circ} \mathrm{C}$ for primer connection, and 30 seconds of $72^{\circ} \mathrm{C}$ for expansion. Finally, the melting reaction occurred. The $\mathrm{Ct}$ related to the reactions was extracted by a software of real time-PCR, and finally, the $\mathrm{Ct}$ mean was recorded twice. The primer used in this research is presented in Table 2 .

Table 2. Primers used in the research.

\begin{tabular}{cccc}
\hline Gene & Host & Forward Primer & Reverse Primer \\
\hline Desnutrin & Rat & GACAGCTCCACCAACATCCA & AAGTCCATCTCGGTAGCCCT \\
$\beta$-Actin & Rat & CACGGCATTGTCACCAACTG & GCTGGGGTGTTGAAGGTCTC \\
\hline
\end{tabular}

To quantify the levels of the target gene expression, the formula $2^{\wedge}(-\Delta \Delta \mathrm{ct})$ was used. 
Statistical method. Descriptive statistics were used to categorize the raw data and describe the data. The Kolmogorov-Smirnov test (KS) was used to verify the natural distribution of the data; the Levene Test was used to verify the equality of variances. The independent t-test was used to compare intergroup changes. A significance level of $\mathrm{p}<0.05$ was provided for all the statistical tests. Statistical analysis was conducted by using the SPSS 16 software and drawing charts using the Excel 2007 software.

\section{RESULTS}

Firstly, the early weight changes of rats after 12 weeks of high-fat diet and after six weeks of standard diet along with continuous training and high-intensity interval training have been reported in Table 3.

Desnutrin Results in the Adipose Tissue. In the present study, the gene expression level of desnutrin in the continuous training group was higher than the high-intensity interval training group and there was a statistically significant difference $(p=0.004)$ (Figure 1).

Table 3. Average and standard deviation of groups' weights.

\begin{tabular}{ccccc}
\hline Group & Before 12 weeks & After 12 weeks & After 6 weeks & Percentage Change \\
\hline Continuous Training & 223 & $320.97 *$ & 308.30 & -6.71 \\
High-Intensity Interval Training & 220 & $325.97^{*}$ & 290 & -15.70 \\
\hline \multicolumn{4}{r}{ *significant differences between pre- and post-12-weekweight. }
\end{tabular}

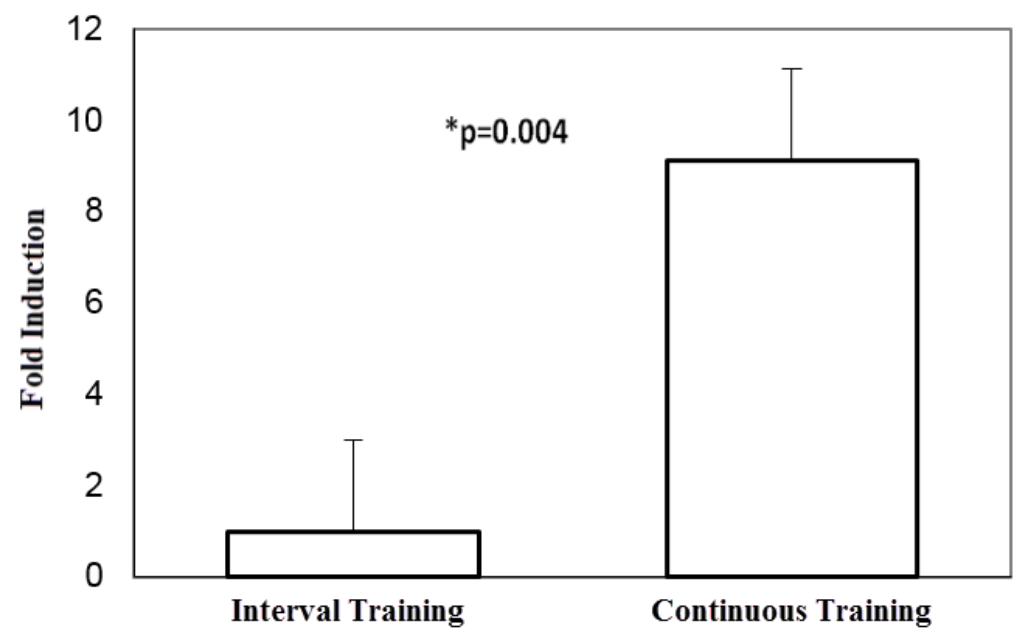

Figure 1: Desnutrin mRNA multi-fold variation ratio of the abdominal subcutaneous adipose tissue in the training group compared to the control group. The data is expressed as mean \pm SEM. Each column is for each group including 10 rats.

Desnutrin Results in the Muscle tissue. In the present study, the gene expression level of desnutrin in the high-intensity interval training group was higher than the continuous training group, but there was no statistically significant difference $(\mathrm{p}=0.415)$ (Figure 2).

\section{DISCUSSION}

In our study, it was determined that the desnutrin gene expression level of the subcutaneous adipose tissue in the continuous training group was higher than the high-intensity interval training group, and there was a statistically significant difference. So far, not much research has been conducted about the effect of highintensity interval training on desnutrin/ATGL. Aerobic exercise training can increase the expression of desnutrin/ATGL in the adipose tissue $(15,16)$. Here, the cause of an approximately eight-fold increase in the desnutrin gene 
expression of the subcutaneous adipose tissue in the continuous training group compared to the high-intensity interval training could be due to the intensity and the duration of training. As the use of fat increases at lower intensities and over greater durations of training $(17,18)$, its main source is the triglyceride of the adipose tissue. Therefore, it is expected that a further increase in desnutrin/ATGL of the subcutaneous adipose tissue in continuous training compared to the high-intensity interval training can be justified. Moreover, high weight loss in the high-intensity interval training group compared to the continuous training group may have led to a decrease in fat tissue mass, and as a result, lipolysis and the source of adipose tissue fatty acids in this group (high-intensity interval training) have been decreased and caused this difference in the gene expression.

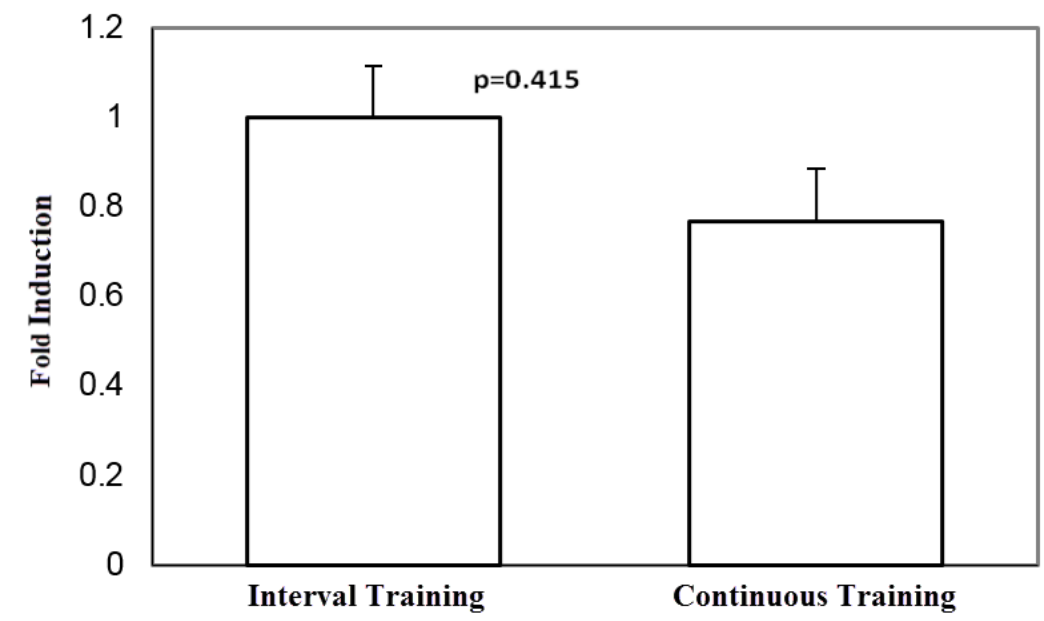

Figure 2: Desnutrin mRNA multifold variation ratio of the quadriceps femoris muscle tissue in the training group compared to the control group. Thedata expressed as mean \pm SEM. Each column is for each group including 10 rats

Moreover, in the present study, the desnutrin gene expression level of the quadriceps femoris muscle tissue in the highintensity interval training group was higher than the continuous training group, but there was no statistically significant difference. In this study, high-intensity interval training slightly increased the desnutrin gene expression of the quadriceps muscle tissue in comparison to continuous training group. Owing to adaptation with exercise training, the use of intramuscular triglyceride stores increases during exercise $(8,19)$. On the other hand, localized muscle energy consumption in the thighs during the high-intensity interval training is very intense and greater than other parts of the body, resulting in the use of intramuscular fat in high-intensity interval training in the thigh and the quadriceps of femoris muscle (20). Therefore, this has led to a further increase in lipolysis, which results in muscular desnutrin/ATGL gene expression. Perhaps, the manipulation of intensity and the duration of the high-intensity interval training could make this difference more significant. However, high-intensity interval training showed a 1.2-fold increase in the desnutrin gene expression of the quadriceps femoris muscle tissue in comparison to the continuous training group.

Generally, due to adaptation with exercise training and an encounter with the health risks associated with obesity, lipolysis markers of the adipose tissue and the muscle tissue, including desnutrin/ATGL are increased, which lead to the reduction of complications of obesity through weight loss, increase of lipolysis, increase of mitochondrial fat oxidation, and a change of white adipose tissue phenotype to be brown. In addition, as a positive adaptation, exercise training increases the intra myocellular triglyceride stores, which is followed by an increase in the level of intramuscular desnutrin/ATGL, and possibly the improvement of insulin-resistance due to obesity. 


\section{CONCLUSION}

As a conclusion, in subcutaneous adipose tissue, continuous training has a greater effect on the desnutrin gene expression than high-intensity interval training. In the quadriceps femoris muscle tissue, however, there is no difference between these two training exercises. Future investigations can study the effect of exercise training on desnutrin along with a high-fat diet. Moreover, the effect of resistance training can be studied along with the two types of training protocols studied here.

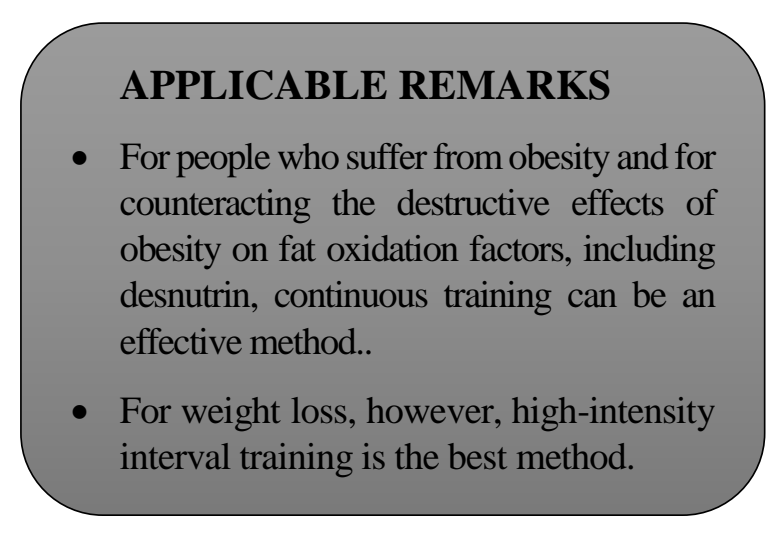

\section{REFERENCES}

1. Eckel RH, Kahn SE, Ferrannini E, Goldfine AB, Nathan DM, Schwartz MW, et al. Obesity and type 2 diabetes: what can be unified and what needs to be individualized? Diabetes Care. 2011;34(6):1424-30.

2. Knapp M, Gorski J. The skeletal and heart muscle triacylglycerol lipolysis revisited. J Physiol Pharmacol. 2017;68(1):3-11.

3. Wolf G. The mechanism and regulation of fat mobilization from adipose tissue: desnutrin, a newly discovered lipolytic enzyme. Nutr Rev. 2005;63(5):166-70.

4. Watt MJ, Cheng Y. Triglyceride metabolism in exercising muscle. Biochim Biophys Acta. 2017.

5. Villena JA, Roy S, Sarkadi-Nagy E, Kim KH, Sul HS. Desnutrin, an adipocyte gene encoding a novel patatin domain-containing protein, is induced by fasting and glucocorticoids: ectopic expression of desnutrin increases triglyceride hydrolysis. J Biol Chem. 2004;279(45):47066-75.

6. Ahmadian M, Abbott MJ, Tang T, Hudak CS, Kim Y, Bruss M, et al. Desnutrin/ATGL is regulated by AMPK and is required for a brown adipose phenotype. Cell Metab. 2011;13(6):739-48.

7. Larsen S, Danielsen JH, Sondergard SD, Sogaard D, Vigelsoe A, Dybboe R, et al. The effect of high-intensity training on mitochondrial fat oxidation in skeletal muscle and subcutaneous adipose tissue. Scand J Med Sci Sports. 2015;25(1):e59-69.

8. Morton TL, Galior K, McGrath C, Wu X, Uzer G, Uzer GB, et al. Exercise Increases and Browns Muscle Lipid in High-Fat Diet-Fed Mice. Front Endocrinol (Lausanne). 2016;7:80.

9. Ahmadian M, Duncan RE, Varady KA, Frasson D, Hellerstein MK, Birkenfeld AL, et al. Adipose overexpression of desnutrin promotes fatty acid use and attenuates diet-induced obesity. Diabetes. 2009;58(4):855-66.

10. Hoshino D, Yoshida Y, Kitaoka Y, Hatta H, Bonen A. High-intensity interval training increases intrinsic rates of mitochondrial fatty acid oxidation in rat red and white skeletal muscle. Appl Physiol Nutr Metab. 2013;38(3):326-33.

11. Zhang H, Tong TK, Qiu W, Zhang X, Zhou S, Liu Y, et al. Comparable Effects of High-Intensity Interval Training and Prolonged Continuous Exercise Training on Abdominal Visceral Fat Reduction in Obese Young Women. J Diabetes Res. 2017;2017:5071740.

12. Alsted TJ, Nybo L, Schweiger M, Fledelius C, Jacobsen P, Zimmermann R, et al. Adipose triglyceride lipase in human skeletal muscle is upregulated by exercise training. Am J Physiol Endocrinol Metab. 2009;296(3):E445-53.

13. Afzalpour ME, Chadorneshin HT, Foadoddini M, Eivari HA. Comparing interval and continuous exercise training regimens on neurotrophic factors in rat brain. Physiol Behav. 2015;147:78-83.

14. Storlien LH, James DE, Burleigh KM, Chisholm DJ, Kraegen EW. Fat feeding causes widespread in vivo insulin resistance, decreased energy expenditure, and obesity in rats. Am J Physiol. 1986;251(5 Pt 1):E576-83.

15. Ogasawara J, Sakurai T, Kizaki T, Ishibashi Y, Izawa T, Sumitani Y, et al. Higher levels of ATGL are associated with exercise-induced enhancement of lipolysis in rat epididymal adipocytes. PLoS One. 2012;7(7):e40876.

16. Yao-Borengasser A, Varma V, Coker RH, Ranganathan G, Phanavanh B, Rasouli N, et al. Adipose triglyceride lipase expression in human adipose tissue and muscle. Role in insulin resistance and response to training and pioglitazone. Metabolism. 2011;60(7):1012-20.

17. Bae JY, Woo J, Roh HT, Lee YH, Ko K, Kang S, et al. The effects of detraining and training on adipose tissue lipid droplet in obese mice after chronic high-fat diet. Lipids Health Dis. 2017;16(1):13.

18. Louche K, Badin PM, Montastier E, Laurens C, Bourlier V, de Glisezinski I, et al. Endurance exercise training upregulates lipolytic proteins and reduces triglyceride content in skeletal muscle of obese subjects. J Clin Endocrinol Metab. 2013;98(12):4863-71. 
19. Kim SJ, Tang T, Abbott M, Viscarra JA, Wang Y, Sul HS. AMPK Phosphorylates Desnutrin/ATGL and HormoneSensitive Lipase To Regulate Lipolysis and Fatty Acid Oxidation within Adipose Tissue. Mol Cell Biol. 2016;36(14):1961-76.

20. Koichiro Azuma YO, Shogo Tabata, Fuminori Katsukawa, Hiroyuki Ishida, Yuko Oguma, Toshihide Kawai, Hiroshi Itoh, Shigeo Okuda, Shuji Oguchi, Atsumi Ohta, Haruhito Kikuchi, Mitsuru Murata, Hideo Matsumoto. Decrease in regional body fat after long-term high-intensity interval training. The Journal of Physical Fitness and Sports Medicine 2017;16:103-10. 